\title{
STUDY ON THE THERMAL AND IMPACT RESISTANCE PROPERTIES OF MICRO PA66/PU SYNERGISTICALLY REINFORCED MULTI-LAYERED BIAXIAL WEFT KNITTED FABRIC COMPOSITES
}

\author{
Yexiong Qi ${ }^{1,2, *}$, Waqar Iqbal', Runze Shao', Yanjin Shi ${ }^{1}$ \\ 1 School of Textile Science and Engineering, Tiangong University, Tianjin, 300387, China \\ 2 Key Laboratory of Advanced Textile Composites, Ministry of Education, Institute of Textile Composites, Tiangong University, Tianjin 300387, China \\ ${ }^{*}$ Corresponding author: E-mail: qiyexiong@tiangong.edu.cn
}

\begin{abstract}
:
In this paper, the influence of micro PA66/PU in multi-layered biaxial weft knitted (MBWK) fabric reinforced composites on thermal and impact resistance was studied. The main objective was to investigate the role of micro PA66/PU in terms of improving material performance. The results showed that the addition of micro PA66/PU improved the thermal stability of the MBWK composite. It is observed that the onset degradation temperatures increased by $1.6^{\circ} \mathrm{C}$ in thermo-gravimetric analysis (TGA) test and the $\mathrm{Tg}$ increased by $2.8^{\circ} \mathrm{C}$ in the dynamic mechanical analysis (DMA) test. Besides, the impact energy absorption of composites increased by $5.3 \%$ after the addition of micro PA66/PU. The addition of micro PA66/PU effectively reduced the impact damage area from the failure morphology after impact. In simple words, the addition of micro PA66/PU effectively improves the comprehensive properties of composites.
\end{abstract}

\section{Keywords:}

Micro PA66/PU, MBWK composite, thermal stability, impact resistance, combustion resistance

\section{Introduction}

Based on the lack of real leather production and people's constant attention to animal protection, microfiber leather with excellent chemical corrosion resistance and physical and mechanical properties gradually replace real leather products. Besides, it has almost the same tactile impression and elasticity as dermis production. In 2016, the capacity of domestic microfiber leather production has exceeded 200 million square meters which is four times more than the domestic production in 2010. However, the huge pollution comes with the microfiber leather production process. PA66/PU mixed waste (PPMW), which is a waste in the production of microfiber leather, is difficult to be separated and degraded and it has a bad influence on the environment. According to statistics, an enterprise with an annual output of 6 million square meters of microfiber leather produces 200 tons of waste. High cost and difficult handling bring great threat to the environment.

Polyamide 66 (PA66) and polyurethane (PU), which are the major engineering materials, are featured with excellent thermal stability, weather-shield durability, chemical resistance, excellent mechanical performance, and easy processing, and hence are increasingly used in mechanical and/or structural applications [1-4]. In recent years, many applications of PA66 and PU were studied for different functions through modifying and compounding. Rigid foam plastics can be prepared by adding different flame retardants on the base of PU. Zheng et al. [5] prepared the flame retarded rigid PU foam through using polyols and diisocyanates with a modified intumescent flame retardant (MIFR) via polyoxyethylene nonylphenol ether (surfactant TX-10), and Peng et al. [6] formed the rigid foam composites by combining the rigid PU foam and panel, from which the excellent flame retardant performance was got (the optimal limiting oxygen index (LOI) was $29.5 \%$ ). To improve the flame retardancy of PA66, Lyu et al. [7, 8] modified the PA66 through end-pieces capping technology, the total heat release rate significantly reduced by $36.3 \%$ and the LOI reached $29.5 \%$. Similarly, PA66 and PU had very good application prospects in the field of medical and health care. Most importantly, PA66 and PU show good impact resistance in practical application. Bangash et al. [9] and Poonsub et al. [10] introduced dynamic $\mathrm{PU}$ into CFRP laminated composite to obtain dynamic twophase composites with repairable, recyclable, self-healing, and enhanced impact resistance properties. In addition to these advantages, PA66 and PU also had great advantages in oilwater separation [11-14], thermal performance [15-17], sound absorption [18, 19], electrical performance [20, 21], and wear resistance [22, 23].

Epoxy is the common matrix in fiber-reinforced composites. Its highly cross-linked structure [24] has many useful properties, such as high modulus of elasticity [25], high failure strength [25], high creep resistance [26], and etc. However, most of the epoxy is brittle, which will lead to the impact resistance of the 
three-dimensional shell material with multi-layered biaxial weft knitted (MBWK) fabric as reinforcement and epoxy as matrix cannot meet the requirements. Therefore, how to restrain the thermal stability of MBWK fabric reinforced three-dimensional shell and improve the impact resistance of the shell is the most important research topic. The toughness of epoxy composite with high brittleness can be improved by using PA66 and PU at the micron level, so that the impact resistance of the composite can be improved. Hence, it was thought that it was necessary to study characterization of micro PA66/PU, which improved the impact resistance performance of materials.

Hence, the study of characterization and reuse of PPMW not only improved the performance of materials but also protected the environment. In this work, the MBWK fabrics reinforced micro PA66/PU epoxy composites (MFPPEC) plates were manufactured by vacuum bag forming process. The thermal, mechanical, and flame retardancy properties were reported by SEM, TGA, DMA, X-ray, and mechanical test, respectively.

\section{Materials and methods}

\subsection{Materials}

Micro PA66/PU is supplied by Shandong Tongda Island New Materials Co., Ltd (Shandong, China). It is the waste obtained from the production of microfiber leather. Random samples are prepared and it is observed that the diameter of the fibers ranged from $1 \mu \mathrm{m}$ to $18 \mu \mathrm{m}$, and most of the fibers are fine fibers with a size of $2 \mu \mathrm{m}$. The fiber length ranges from $20 \mu \mathrm{m}$ to $2 \mathrm{~mm}$, most of them are short fibers, and the length is $<100 \mu \mathrm{m}$. Heat resist modified epoxy resin (JC-085A) and modified anhydrides curing agent (JC-085B) were purchased from Changshu Jiafa Chemical Co., Ltd (Jiangsu, China). The resin information of JC-085A/B is listed in Table 1. PA66 and PU are bonded together with micro PA66/PU materials. Micro PA66/ $\mathrm{PU}$, a waste in the production of microfiber leather, is difficult to be separated and degraded, which has hazardous effects on the environment. High cost and difficult handling of PA66 and

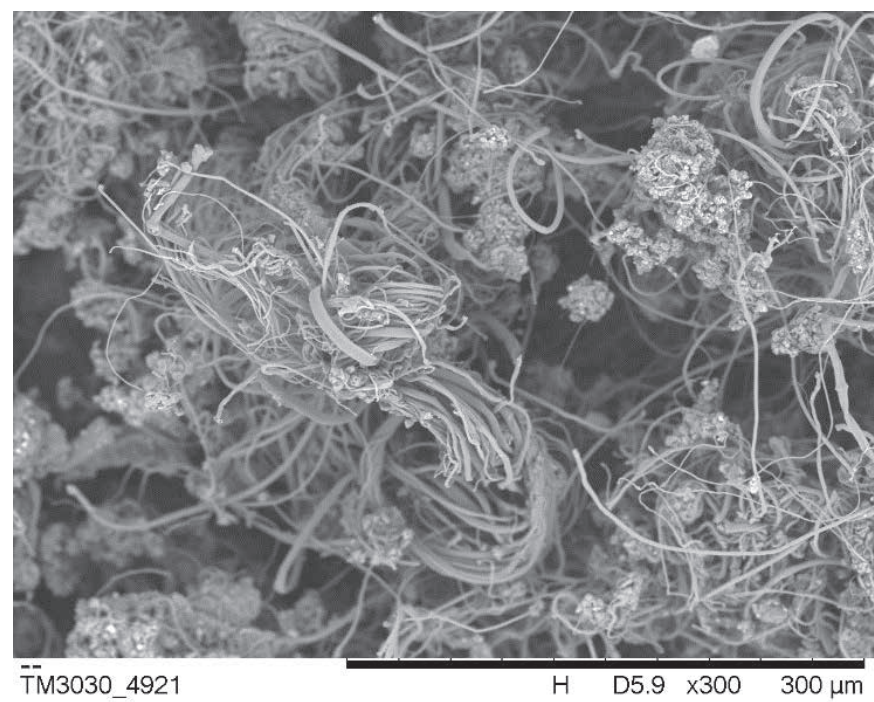

Figure 1. SEM image of micro PA66/PU.
PU make it as a threat to the environment. Fortunately, PA66 and PU have excellent thermal, mechanical, flame retardant, impact resistance, and other properties, which make these two materials as the best choice so far, in the application in a broad prospect. PA66 exists in the state of fiber, but PU is in the state of granule. MBWK fabric, the properties and structure of which are shown in Table 2, is produced in Key Laboratory of Advanced Textile Composites, Tiangong University (Figure 1).

\subsection{Preparation of composites}

Micro PA66/PU reinforced epoxy composites were manufactured by vacuum bag forming process with $0.5 \%$ micro PA66/PU contents. The approximate powdery materials were dried at $100^{\circ} \mathrm{C}$ for $2 \mathrm{~h}$ in an oven. Then it was mixed in a high-speed mechanical mixture at $100 \mathrm{rpm}$ for $20 \mathrm{~min}$. After that, it was put in a vacuum drying oven to remove air bubbles from the mixture. Finally, the micro PA66/PU reinforced epoxy composites were obtained via vacuum bag forming process. The MBWK fabrics reinforced epoxy composites (MFEC) and MBWK fabrics reinforced micro PA66/PU epoxy composites (MFPPEC) were manufactured as shown in Figure 2. And the structure of MBWK fabrics is also shown in Figure 2. Standard specimens for impact test were ASTM D256.s.

\subsection{Characterization}

Thermal and thermo-mechanical properties were analyzed by thermogravimetric analysis (TGA) and dynamic mechanical analysis (DMA), respectively. In the TGA test, TG 209 F3 tarsus thermo-gravimetric instrument was used and nitrogen atmosphere was used in the full range. The temperature used for the test was in the range of $25-800^{\circ} \mathrm{C}$ and the heating rate was $10^{\circ} \mathrm{C} / \mathrm{min}$. In the DMA test, NETZSCH DMA 242 instrument was used. The temperature range was $30-350^{\circ} \mathrm{C}$, while the heating rate is $2^{\circ} \mathrm{C} / \mathrm{min}$, the frequency is $1 \mathrm{~Hz}-2 \mathrm{~Hz}-5 \mathrm{~Hz}-$ $10 \mathrm{~Hz}$, and the deformation mode is three-point bending. The sample size is $40 \mathrm{~mm} \times 10 \mathrm{~mm} \times 3 \mathrm{~mm}$. X-ray tomography (Carl Zeiss X-ray Microcopy, Xradia Versa 510) and SEM (Hitachi, TM3030) were used to get the distribution of micro PA66/PU

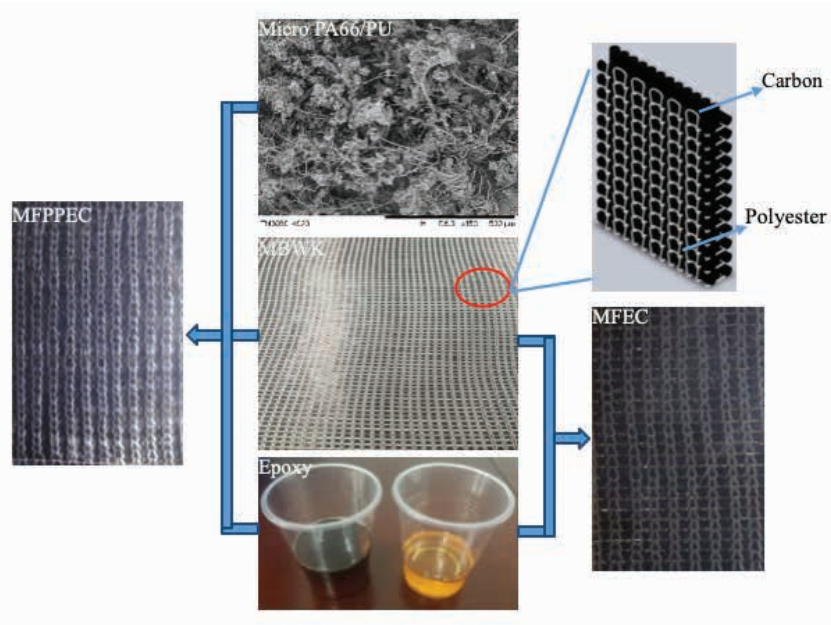

Figure 2. Photographs of MFEC and MFPPEC. 
Table 1. The resin information of JC-085A/B

\begin{tabular}{|c|c|}
\hline JC-085A/B & Performance \\
\hline Density $/\left(\mathrm{g} / \mathrm{cm}^{3}\right)$ & 1.25 \\
\hline Liquid form $/ \mathrm{mpa} \cdot \mathrm{s}\left(25^{\circ} \mathrm{C}\right)$ & $800-1000$ \\
\hline Heat deflection temperature (HDT) $/{ }^{\circ} \mathrm{C}$ & $220-240$ \\
\hline Glass transition temperature $(\mathrm{Tg}) /{ }^{\circ} \mathrm{C}$ & $250-260$ \\
\hline Tensile strength/MPa & $40-50$ \\
\hline Tensile modulus/MPa & $1600-1800$ \\
\hline Elongation at break/MPa & $4-5$ \\
\hline Flexural strength/MPa & $100-110$ \\
\hline Flexural modulus/MPa & $3100-3300$ \\
\hline Impact strength/(KJ/m $\left.{ }^{2}\right)$ & $12-15$ \\
\hline
\end{tabular}

materials and the structure of MBWK in the composites. Impact tests were performed on a universal testing machine (Instron 3369) according to ASTM standards. Note that ZCJ9302 drop weight impact testing machine was used. The impact end mass was $2 \mathrm{~kg}$ and the impact energy was $10 \mathrm{~J}$. The specimen size was $150 \mathrm{~mm} \times 100 \mathrm{~mm} \times 2 \mathrm{~mm}$. For each composition, five specimens were tested, from which the mean value and standard deviation (SD) were calculated. The impact fractured surfaces were observed with $\mathrm{VHX}$ microscope and X-ray tomography to study topographical features.

\section{Results and discussion}

\subsection{SEM studies on the identification of components and existing states in micro PA66/PU materials}

Based on the principle of PA66 fiber's surface wrinkling in the environment of heated zinc chloride iodine ( $\mathrm{ZCl}$ ) [27], it was

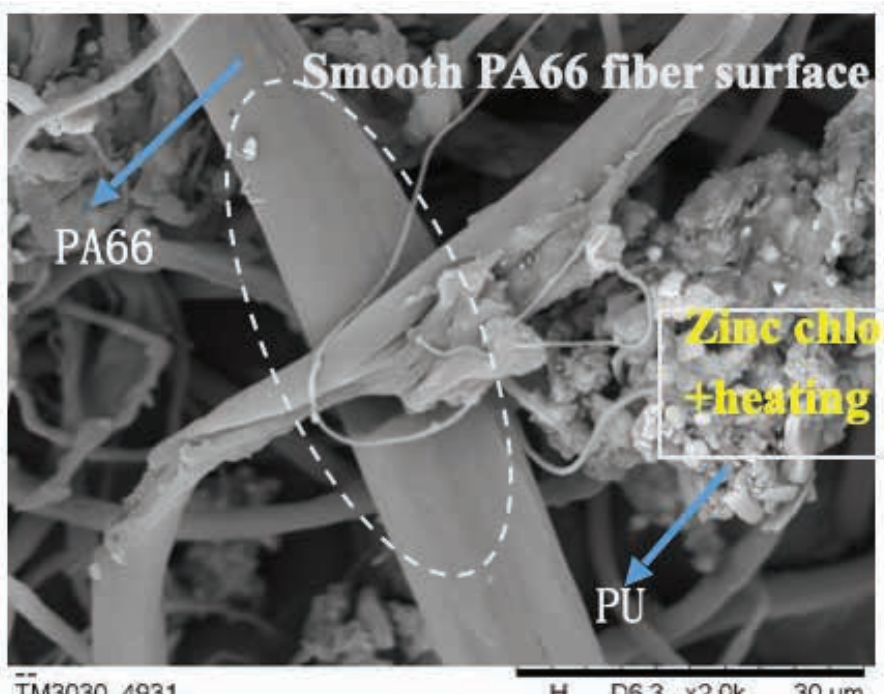

TM3030 4931
Table 2. The properties of MBWK fabric

\begin{tabular}{|c|c|}
\hline MBWK fabric & Parameter \\
\hline Grams per square meter $\left(\mathrm{g} / \mathrm{m}^{2}\right)$ & 635.6 \\
\hline Grams per square meter of weft yarns $\left(\mathrm{g} / \mathrm{m}^{2}\right)$ & 418.8 \\
\hline Grams per square meter of warp yarns $\left(\mathrm{g} / \mathrm{m}^{2}\right)$ & 188.4 \\
\hline Grams per square meter of knitting yarns $\left(\mathrm{g} / \mathrm{m}^{2}\right)$ & 28.4 \\
\hline Thickness (mm) & 0.7 \\
\hline Weft density (needles/inch) & 13.5 \\
\hline Warp Density (needles/inch) & 12 \\
\hline Carbon fiber volume fraction $(\%)$ & 34.5 \\
\hline
\end{tabular}

very easy to identify PA66 in the micro PA66/PU materials. The SEM image of micro PA66/PU's treated by $\mathrm{ZCI}$ has been represented in Figure 3. The surface of PA66 fiber showed obvious wrinkling and a large number of cavities after heating when it was soaked in the solution of ZCl. However, PU did not have any obvious change. The existed state of each component was clearly distinguished and determined. It can be clearly seen from the Figure 3 that PA66 fiber and PU particles are bonded together to form a special pile ball structure and are intertwined with each other. This structure can effectively improve the interface between epoxy resin and fabric, and prevent the propagation of cracks during the process of MFPPEC manufacturing.

\subsection{Thermogravimetric analysis}

A heating rate of $10^{\circ} \mathrm{C} / \mathrm{min}$ is conducted in air and corresponding weight loss was recorded. The small amount of sample was heated from $25^{\circ} \mathrm{C}$ to $900^{\circ} \mathrm{C}$, and Figure 4 showed the thermal stability of composites. Micro PA66/PU reinforced epoxy composite showed slightly higher thermal stability than pure epoxy resin. At $900^{\circ} \mathrm{C}$, micro PA66/PU reinforced epoxy

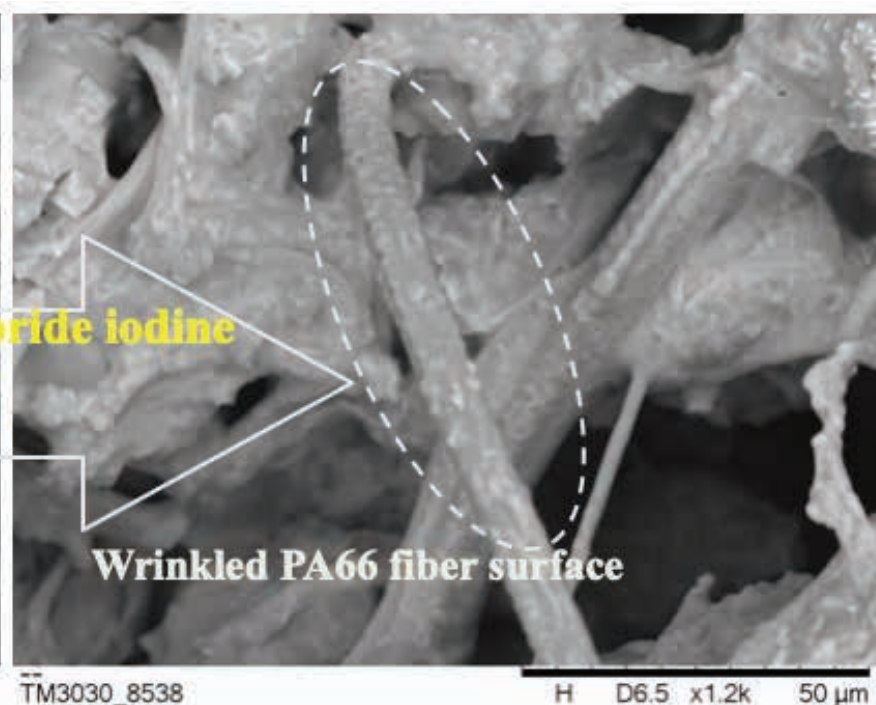

Figure 3. SEM image of micro PA66/PU by ZCI treatment. 
composite showed $15.51 \%$ weight residue whereas pure epoxy resin showed $14.77 \%$ weight residue as it had a certain content of micro PA66/PU. And both materials have very close onset degradation temperatures for pure epoxy resin and micro PA66/PU composite, which were $243.06^{\circ} \mathrm{C}$ and $246.66^{\circ} \mathrm{C}$, respectively. Besides, the range of near onset degradation temperature indicated that the thermal stability of both materials was same. Further, comparison of TGA curves of pure epoxy resin and micro PA66/PU reinforced epoxy composite showed relatively similar thermal stability pattern.

\subsection{Dynamic mechanical analysis}

The storage modulus ( $\left.E^{\prime}\right)$ curve, loss in modulus ( $\left.E^{\prime \prime}\right)$ curve, and loss factor ( $\tan \delta$ ) for pure epoxy resin and $0.5 \%$ micro PA66/PU materials reinforced composites were represented in Figure 5, which depicted the variation of $E^{\prime}, E^{\prime \prime}$, and $\tan \delta$ as a function of temperature at a temperature range of $30^{\circ} \mathrm{C}$ to $350^{\circ} \mathrm{C}$. The $\mathrm{Tg}$ of $0.5 \%$ micro PA66/PU materials reinforced composite exhibited higher value $\left(228.9^{\circ} \mathrm{C}\right)$ than pure epoxy resin $\left(216.1^{\circ} \mathrm{C}\right)$, which indicated that addition of micro PA66/PU materials improved the temperature property of the material. The storage modulus of both composites decreased with increase in temperature above Tg; a similar trend of the curve $E^{\prime}$ has been observed against the reinforced epoxy composite materials and $0.5 \%$ micro PA66/PU materials. Due to the excellent thermal stability

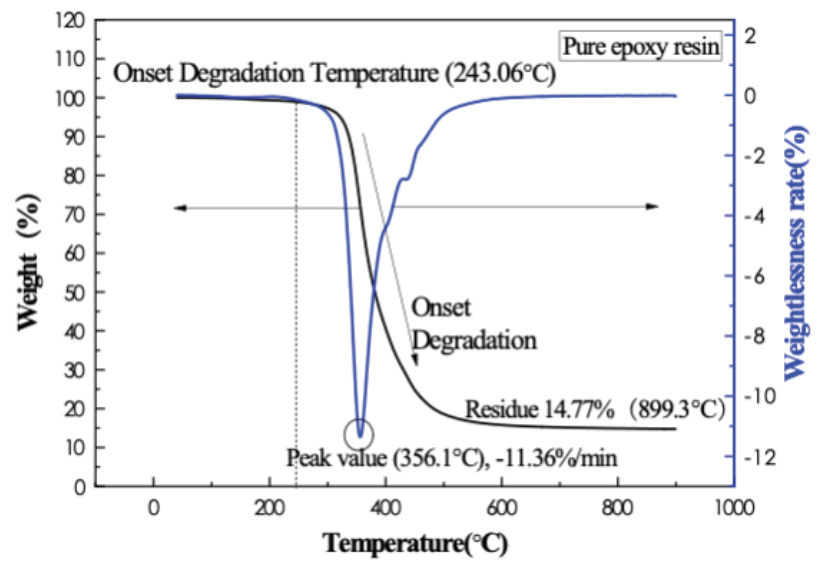

(a)

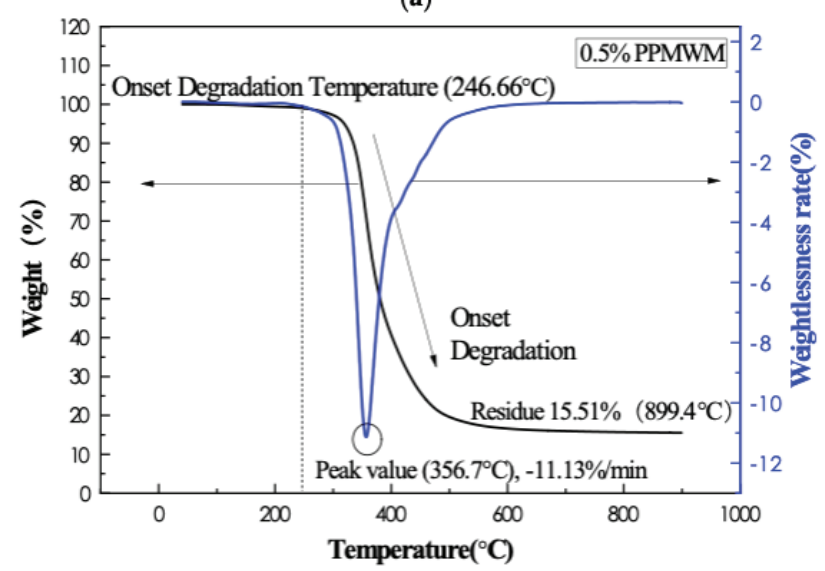

(b)

Figure 4. TGA data of pure epoxy and $0.5 \%$ micro PA66/PU reinforced epoxy composite under air atmosphere at $10^{\circ} \mathrm{C} / \mathrm{min}$. (a) pure epoxy resin; (b) $0.5 \%$ micro PA66/PU reinforced epoxy composite. TGA, thermo-gravimetric analysis. of high-performance fibers, the thermal stability of composites mainly depended on the properties of epoxy resin. The DMA analysis showed that the addition of $0.5 \%$ micro PA66/PU materials improved the performance of epoxy resin. Therefore, the modified composite with micro PA66/PU materials shows improvement in the thermal performance.

\subsection{Structural analysis of composites}

X-ray tomography was carried out to investigate the structure of MBWK fabric in the composites. Figure 6 shows the MBWK fabric, which was the reinforcement of MFPPEC. Figure $6 a$ clearly exhibited the reinforcement structure in composites. The high-performance fibers were arranged in parallel and straight states without interlacing each other. The mechanical properties of fiber materials can be fully developed. Moreover, effective dispersion of the kinetic energy obtained from the impact load can be improved. The black part in the Figure 6a was $0.5 \%$ micro PA66 / PU reinforced epoxy. Due to the presence of micro materials, the interface of materials was increased. When the material received the impact load, the material can effectively absorb the impact kinetic energy and improve the impact resistance of the material. SEM has been carried out to investigate the distribution of micro PA66/PU. PA66 fibers and $\mathrm{PU}$ granule were distributed in epoxy resin randomly, and they

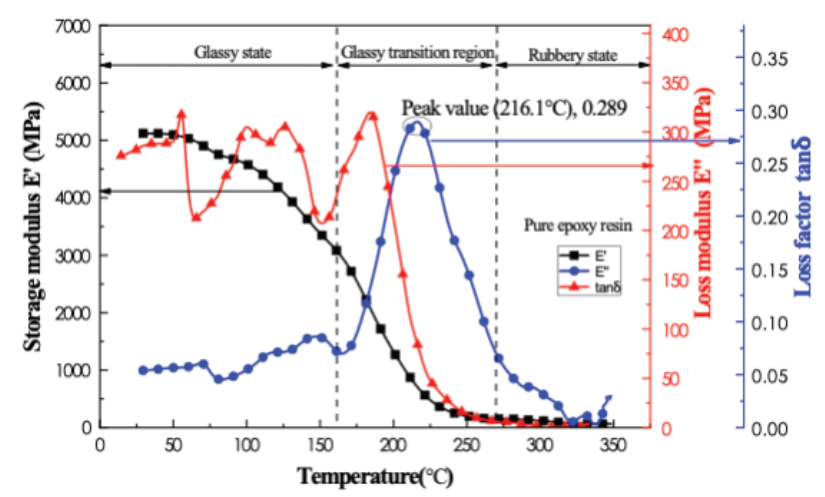

(a)

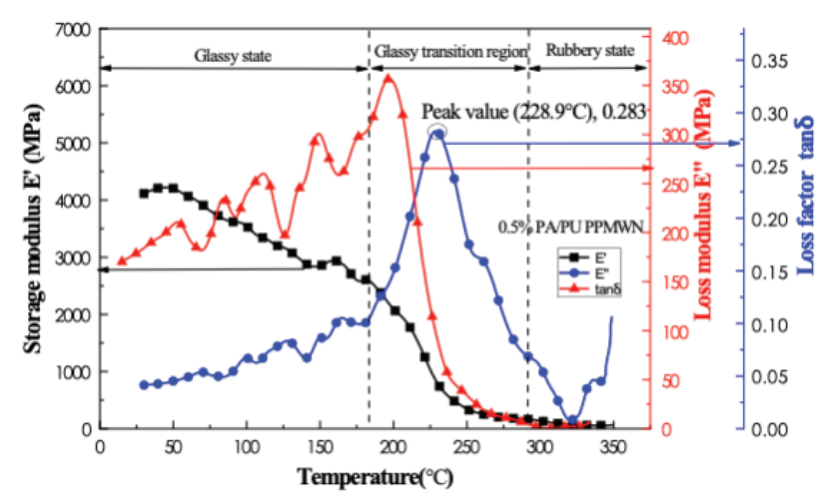

(b)

Figure 5. Storage modulus, loss modulus, and tan $\delta$ as a function of temperature of pure epoxy and $0.5 \%$ micro PA66/PU reinforced epoxy composite. (a) pure epoxy resin and (b) $0.5 \%$ micro PA66/PU reinforced epoxy composite. 


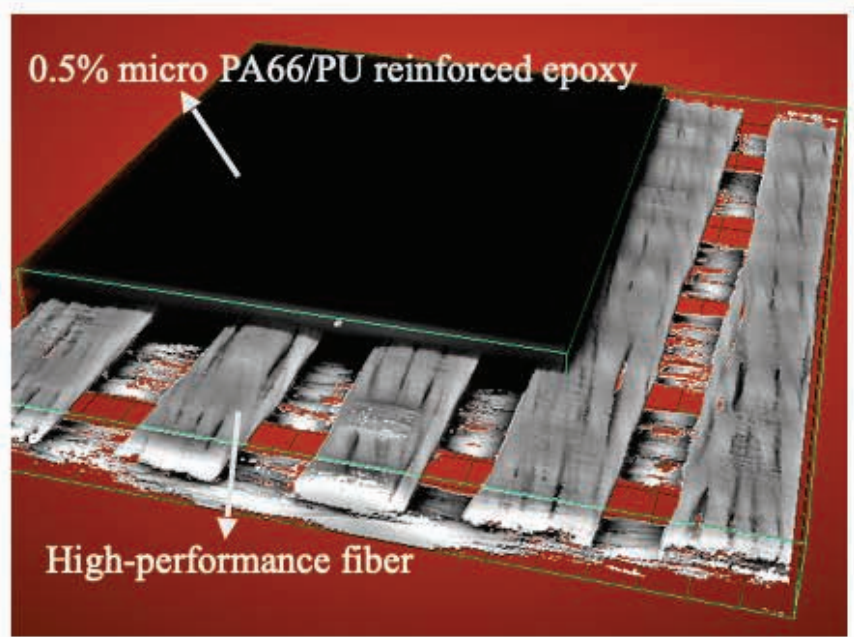

(a)

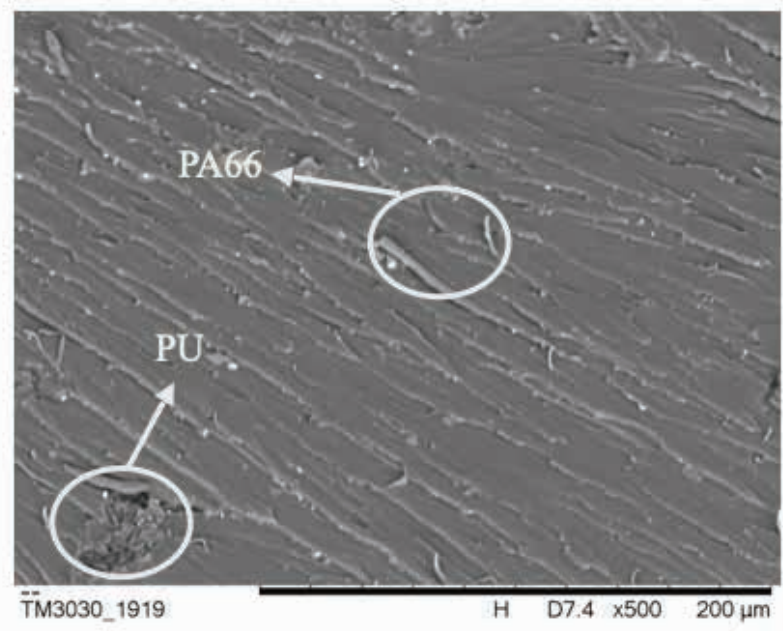

(b)

Figure 6. X-ray tomography and SEM of micro PA66/PU reinforced epoxy composite. (a) X-ray tomography and (b) SEM.

did not have integrated form and distribution. Figure $6 \mathrm{~b}$ showed the random distribution of micro PA66/PU.

\subsection{Impact resistant properties}

Figure 7 shows the dynamic response curves of MFEC and MFPPEC. The peak of MFEC and MFPPEC were close, which indicated that micro PA66/PU has little effect on the resistance to impact load. However, the impact energy absorption of MFEC is $5.2 \mathrm{~J}$, which was slightly lower than that of MFPPE that is $5.49 \mathrm{~J}$. The increasing ratio was $5.3 \%$. The main reason behind that was the addition of micro PA66/PU which increased the interface of materials and the interface's cracking was needed to consume the impact energy. At the same time, the addition of micro PA66/PU increased the interface performance between fabrics and resins, which also played a very important role in terms of impact energy consumption.

Figure 8 shows the failure morphology of MFEC and MFPPEC after impact. There was as such no obvious impact damage trace on the front side of the samples, but contrarily apparent impact morphology appeared on the back side, which indicated that the back of composites suffered greater impact damage. Besides, Figure 8d shows the most apparent impact area than that of given in the Figure $8 \mathrm{~b}$ and it was the evidence to conclude that the addition of PPMW significantly improved the impact resistance of the composites. With the addition of micro PA/ $\mathrm{PU}$ materials, large specific surface area can greatly improve the contact area in the composite system due to the existence of surface interface effect and small size effect, which can help the load move rapidly from the matrix to the reinforcement, so that it could avoide stress concentration and effectively prevent the crack propagation of epoxy resin when impact load is applied. Furthermore, micro PA/PU materials can adjust the bonding force between matrix and reinforced fiber to a certain extent and promote the deflection of micro-crack propagation path in matrix to improve the toughening effect.

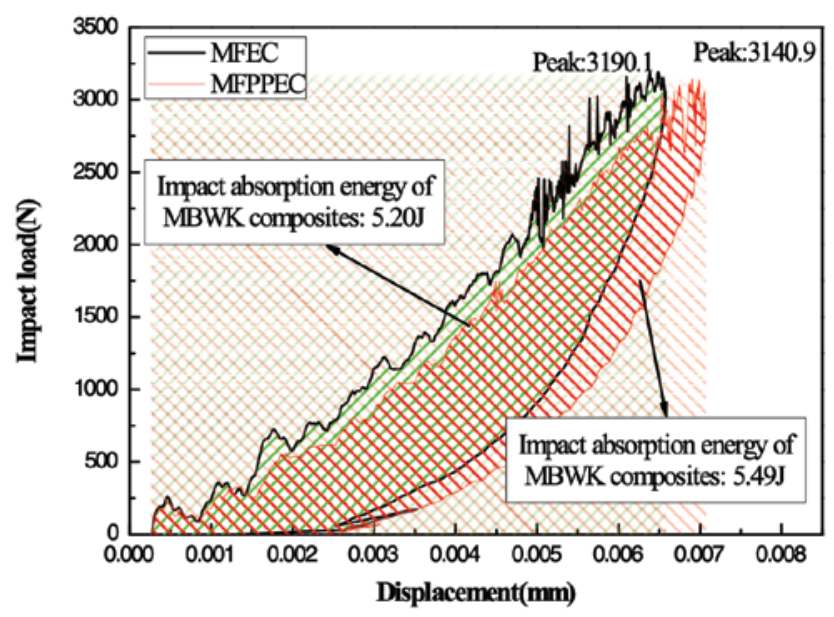

Figure 7. Dynamic response curve of MFEC and MFPPEC.
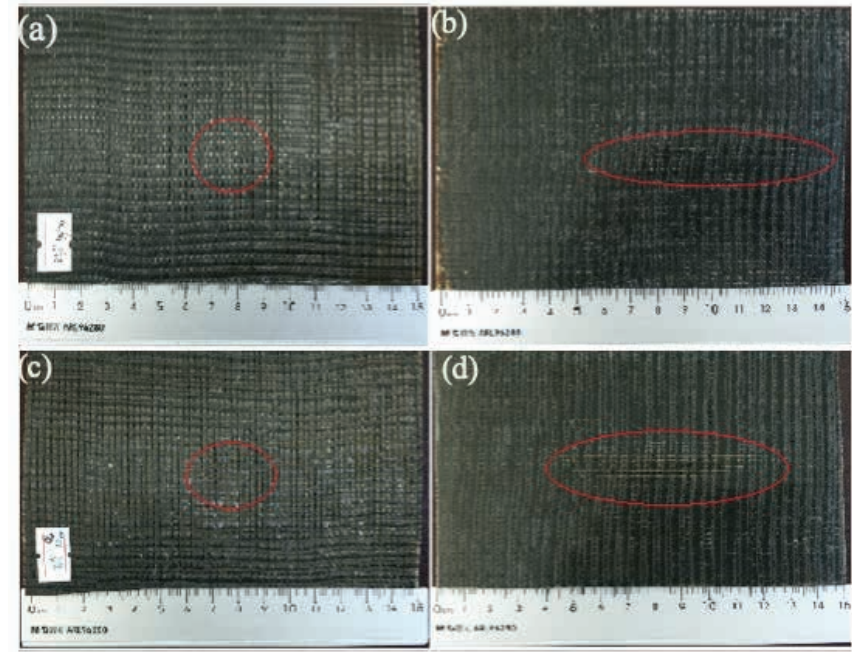

Figure 8. The failure morphology of composites after impact. (a) the impact front of MFPPEC; (b) the impact back of MFPPEC; (c) the impact front of MFEC; and (d) the impact back of MFEC. 


\section{CONCLUSIONS}

Performance evaluation of MBWK epoxy composites based on the structure and thermal characteristic led to following conclusions:

(1) The addition of PPMW did not destroy the thermal stability of the composite but improved it. The onset degradation temperatures increased by $1.6^{\circ} \mathrm{C}$ from TGA test and the $\mathrm{Tg}$ increased by $2.8^{\circ} \mathrm{C}$ from the DMA test.

(2) After the addition of PPMW, the impact energy absorption of composites increased by $5.3 \%$. The addition of PPMW effectively reduced the impact damage area from the failure morphology after impact.

It was thus finally concluded that the addition of micro PA66/ $\mathrm{PU}$ materials effectively improves the properties of composites comprehensively.

\section{ACKNOWLEDGMENTS}

This research was funded by "Aviation Key Laboratory of Science and Technology on Life-support Technology" (grant number 202000290Q2001) and "Tianjin Natural Science Foundation" (grant number 18JCQNJC73300 and 18JCZDJC10020).

\section{Conflicts of Interest}

The authors declare that they have no known competing financial interests or personal relationships that could influence the work reported in this paper.

\section{References}

[1] Zheng, T., Yang, L. Y., Dai, P. B., QinC; Tang, Q. C. (2018). $X P S$ analysis of char residue from an intumescent flame retardant rigid $P U$ composite foam. In: 2nd International Conference on Mechanical Engineering and Applied Composite Materials. Harbin, December, pp. 1-4.

[2] Martin, O., Miroslav, M., Michal, S., Adam, D., Jiri, V., et al. (2020). Polyamide surface layer nano-indentation and thermal properties modified by irradiation. Materials, 13(13), 2915-2931.

[3] Peng, H. K., Wang, X. X., Li T. T., Lou, C. W., Wang, Y. T., et al. (2019). Mechanical properties, thermal stability, sound absorption, and flame retardancy of rigid $P U$ foam composites containing a fire-retarding agent: Effect of magnesium hydroxide and aluminum hydroxide. Polymers for Advanced Technologies, 30(8), 2045-2055.

[4] Abir, T., José, M. M. (2020). Addition of graphene oxide in different stages of the synthesis of waterborne polyurethane-urea adhesives and its influence on their structure, thermal, viscoelastic and adhesion properties. Materials, 13(13), 2899-2924.

[5] Lyu, W. Y., Chen, X., Li, Y. B., Cao, S., Han, Y. M. (2019). Thermal stability and heat release effect of flame retarded PA66 prepared by end-pieces capping technology. Composites Part B: Engineering 167, 34-43.
[6] Lyu, W. Y., Cui, Y. H., Zhang, X. J., Yuan, J. Y., Zhang, W. (2016). Synthesis, thermal stability, and flame retardancy of PA66, treated with dichlorophenylphsophine derivatives. Designed Monomers and Polymers, 19(5), 420-428.

[7] Yan, Y., Zhang, Y., Zuo, Y., Zou, Q., Li, J. D., et al. (2018). Development of Fe3O4-HA/PU superparamagnetic composite porous scaffolds for bone repair application. Materials Letters 212, 303-306.

[8] Zou, Q., Li, J. F., Niu, L. L., Zuo, Y., Li, J. D., et al. (2017). Modified n-HA/PA66 scaffolds with chitosan coating for bone tissue engineering: cell stimulation and drug release. Journal of Biomaterials Science, Polymer Edition 28(13), 1271-1285.

[9] Bangash, M. K., Luzuriaga, A. R., Aurrekoetxea, J., Markaide, N., Grande, H. J., et al.. (2018) Development and characterisation of dynamic bi-phase (epoxy/PU) composites for enhanced impact resistance. Composites Part B: Engineering,155, 122-131.

[10] Poonsub, T., Chanin, K. (2017). Effect of sisal fiber on flexural and impact properties of PMMA-b-PU composites. In: 1st International Conference of the Materials-ResearchSociety-of-Thailand. Chiang Mai, October, 2017, pp. 20022009.

[11] Luo, G., Jin, Z., Dong, Y., Huang, J., Zhang, R., et al. (2018). Preparation and performance enhancements of wear-resistant, transparent PU/SiO2 superhydrophobic coating. Surface Engineering, 34(2), 139-145.

[12] Li, M. F., Wu, Y. Z., Zhong, W. B., Zhao, Q. H., Guo, Q. H., et al. (2019). A novel PU/PVA-co-PE composite nanofiber membrane for water filtration. Journal of Industrial Textiles, 49(4), 431-446.

[13] Wu, Y. J., Xiao, C. F., Zhao, J. (2019). Preparation of an electrospun tubular PU/GE nanofiber membrane for high flux oil/water separation. RSC Advances, 9(58), 3372233732.

[14] Tran, V. H. T., Lee, B. K., (2017). Novel fabrication of a robust superhydrophobicPU@ZnO@Fe3O4@SA sponge and its application in oil-water separations. Scientific Reports UK, DOI: 10.1038/s41598-017-17761-9.

[15] Lingesh, B. V., Ravikumar, B. N., Rudresh, B. M., Madhu, D. (2018). Hybridization effect of micro fillers on mechanical, Thermal and morphological behavior of PA66/PP blend based hybrid thermoplastic composites. Transactions of the Indian Institute of Metals 71(3), 763-773.

[16] Autay, R., Njeh, A., Dammak, F. (2019). Effect of hygrothermal aging on mechanical and tribological behaviors of short glass-fiber-reinforced PA66. Journal of Thermoplastic Composite Materials 32(12), 1585-1600.

[17] Pron, M., Jacquemin, F., Casari, P., Orange, G., Bailleul, J. L., et al. (2019). Thermomechanical characterization of a low viscosity PA66 thermoplastic matrix and associated continuous glass fibre composite under processing conditions. Journal of Composite Materials 53(22), 31693186.

[18] Abd, R. J., Rasmi, N. A., Mohamad, M., Mohamad, N., Lin, S. C., Tee, L. K. (2019). Analysis on noise absorption coefficient for polyurethane filled by waste tire dust (PUWTD) composite foam using response surface method. In: Proceedings of Mechanical Engineering Research Day 2019. MALAYSIA, July, 2019, pp. 88-90. 
[19] Li, T. T., Zhang, X., Wang, H. Y., Dai, W. N., Huang, S. Y., Shiu, B. C. (2019). Sound absorption and compressive property of PU foam-filled composite sandwiches: Effects of needle-punched fabric structure, porous structure, and fabric-foam interface. Polymers for Advanced Technologies, DOI: 10.1002/pat.4781.

[20] Yadav, K., Jha, S., Jassal, M., Agrawal, A. K. (2019). Internally coated highly conductive and stretchable AgNWPU hollow fibers. Polymer, 169, 46-51.

[21] Lee, M., Son, K., Kim, J., Kim, D., Min, B. H., Kim, J. H. (2018). Effect of PA6T on morphology and electrical conductivity in PA66/PA6T/PPE/multiwalled carbon nanotube nanocomposites. Composites Science and Technology, 164, 260-266.

[22] Rudresh, B. M., Ravikumar, B. N. R. (2016)/Investigation on three body abrasive wear behavior of Polyamide66/ Polytetrafluroethylene(PA66/PTFE) blends. In: International Conference on Advanced Materials and Applications (ICAMA). Bengaluru, June, 2016, pp. 25032511.
[23] Rudresh, B. M., Ravikumar, B. N. R. (2018). Influence of experimental parameters on friction and wear mechanisms of PA66/PTFE blend reinforced with glass fiber. Transactions of the Indian Institute of Metals, 71(2), 339-349.

[24] Chowdhury, S. C., Elder, R. M., Sirk, T. W. (2020). Epoxy resin thermo-mechanics and failure modes: Effects of cure and cross-linker length. Composites Part B: Engineering, 186, DOI: 10.1016/j.compositesb.2020.107814.

[25] Li, R. F., Yang, D. G., Zhang, P. (2019). Effects of hightemperature storage on the elasticity modulus of an epoxy molding compound. Materials, 12(4), 684-693.

[26] Xu, X. W., Ma, S. Q., Wang, S. (2020). Dihydrazonebased dynamic covalent epoxy networks with high creep resistance, controlled degradability, and intrinsic antibacterial properties from bioresources. Journal of Materials Chemistry A, 22(8), 11261-11274.

[27] Yu, W. D. (Ed.) (2006). Textile materials. China Textile Press (Beijing). 